\title{
Stereological Changes in Microvascular Parameters in Hippocampus of a Transgenic Rat Model of Alzheimer's Disease
}

\author{
Yaroslav Kolinko ${ }^{\mathrm{a}, \mathrm{b}, *}$, Lucie Marsalova ${ }^{\mathrm{a}, \mathrm{b}}$, Stephanie Proskauer Pena ${ }^{\mathrm{a}}$, Milena Kralickova ${ }^{\mathrm{a}, \mathrm{b}}$ \\ and Peter R. Mouton ${ }^{\mathrm{c}, \mathrm{d}}$ \\ ${ }^{a}$ Biomedical Center, Faculty of Medicine in Pilsen, Charles University, Pilsen, Czech Republic \\ ${ }^{\mathrm{b}}$ Department of Histology and Embryology, Faculty of Medicine in Pilsen, Charles University, Pilsen, \\ Czech Republic \\ ' SRC Biosciences, Tampa, FL, USA \\ ${ }^{\mathrm{d}}$ University of South Florida, Tampa, FL, USA
}

Handling Associate Editor: Jack de la Torre

Accepted 11 August 2021

Pre-press 10 September 2021

\begin{abstract}
.
Background: Microcirculatory factors play an important role in amyloid- $\beta$ (A $\beta$ )-related neuropathology in Alzheimer's disease $(\mathrm{AD})$. Transgenic (Tg) rat models of mutant $\mathrm{A} \beta$ deposition can enhance our understanding of this microvascular pathology.

Objective: Here we report stereology-based quantification and comparisons (between- and within-group) of microvessel length and number and associated parameters in hippocampal subregions in Tg model of $\mathrm{AD}$ in Fischer 344 rats and non- $\mathrm{Tg}$ littermates.

Methods: Systematic-random samples of tissue sections were processed and laminin immunostained to visualize microvessels through the entire hippocampus in $\mathrm{Tg}$ and non-Tg rats. A computer-assisted stereology system was used to quantify microvessel parameters including total number, total length, and associated densities in dentate gyrus (DG) and cornu ammonis (CA) subregions.

Results: Thin hair-like capillaries are common near $\mathrm{A} \beta$ plaques in hippocampal subregions of $\mathrm{Tg}$ rats. There are a $53 \%$ significant increase in average length per capillary across entire hippocampus $(p \leq 0.04)$ in $\mathrm{Tg}$ compared to non- $\mathrm{Tg}$ rats; $49 \%$ reduction in capillary length in DG $(p \leq 0.02)$; and, higher microvessel density in principal cell layers $(p \leq 0.03)$. Furthermore, within-group comparisons confirm Tg but not non-Tg rats have significant increase in number density $(p \leq 0.01)$ and potential diffusion distance $(p \leq 0.04)$ of microvessels in principal cell layers of hippocampal subregions.

Conclusion: We show the Tg deposition of human $A \beta$ mutations in rats disrupts the wild-type microanatomy of hippocampal microvessels. Stereology-based microvascular parameters could promote the development of novel strategies for protection and the therapeutic management of $\mathrm{AD}$.
\end{abstract}

Keywords: Alzheimer's disease, capillary, hippocampus, microvessels, stereology, TgF344-AD rat

\section{INTRODUCTION}

\footnotetext{
${ }^{*}$ Correspondence to: Dr. Yaroslav Kolinko, PhD, Department of Histology and Embryology, Karlovarská 48, Pilsen 301 66, Czech Republic. Tel.: +420 608170 478; E-mail: Yaroslav.Kolinko@lfp.cuni.cz.
}

Microvasculature disruptions in the brain parenchyma, especially in neocortical and hippocampal subregions, are part of the progressive neurodegeneration in brains of patients with 
Alzheimer's disease (AD). These microvascular changes appear closely associated with neuroinflammation caused by microglia activation and release of pro-inflammatory cytokines in response to the deposition of insoluble amyloid- $\beta$ (A $\beta$ ) protein [1]. Clinical studies and postmortem analysis suggest a significant interaction between $A \beta$ deposition and microvascular pathology in a large majority $(\sim 90 \%)$ of patients with confirmed AD [2-5].

The vascular development and anatomy of the rat hippocampus show strong similarities to those in humans. Arterial vascularization of the hippocampus emerges from the collateral branches of the posterior cerebral artery and the anterior choroidal artery, forming the network of superficial hippocampal arteries that branch into the deep intrahippocampal arteries with higher levels of vascularization in ventral as opposed to dorsal hippocampus [6]. Some evidence suggests the stratum pyramidale (pyramidal cells layer) of the Amun's horns (CA) regions of hippocampus contain the highest density of the microvessels [6]. On the venous side, vascularization begins with the intrahippocampal veins that drain into the superficial hippocampal veins [7].

Previous studies of transgenic presenilin mouse models of familial AD report many similarities with the vascular pathology seen in patients with $A D$, including an age-related increase in the frequency of kinked, twisted, and string-like vessels [8]. Adult (7-month-old) double transgenic (APPswe/PS1delta E9) mice show a reduction in total number of capillary segments with no changes in capillary length in white matter (corpus callosum) [9]. These changes may reflect an adaptive response of the capillary network to the neuronal degeneration-related reduction in energy demands [10]. Other studies involving $\mathrm{A} \beta$ deposition in animal models and in cultured endothelial cells report variable degrees of vascular wall degeneration, loss of basal membrane and distorted, swollen nuclei in endothelial cells associated with the formation of micro-hematomas [8, $11,12]$. These small hemorrhages appear to result from $A \beta$ deposition in the tunica media and smooth muscle cells in tunica adventitia [13, 14], leading to accelerated development and progression of amyloid angiopathy in cerebral capillaries [15]. These experimentally induced changes in vascular wall structure cause a generalized increased in the production of extracellular matrix-related proteins [15]. Microscopic analyses reveal a strong association between microvessel (capillary) length and the numbers of synaptic and neuronal mitochondria in the hippocampus [16, 17]. The pericytes that functionally regulate capillary contraction for the maintenance of blood follow [18-20] appear to undergo changes associated with vascular $A \beta$ deposition $[8,21-25]$. The deposition of mutant $A \beta$ in the cell culture also appears to mediate neural stem cell maturation [26] and affect glial cells dysregulation [27]. Finally, antemortem functional magnetic resonance imaging and post-mortem studies of AD patients support the view that degenerative vascular changes lead to impaired vascular remodeling and/or angiogenesis [28, 29].

In the past two decades transgenic ( $\mathrm{Tg}$ ) mouse models of $\mathrm{AD}$ have shown the vascular consequences of expression of human $\mathrm{AD}$ mutants and deposition of $A \beta$ peptides $[8,9,23,24,26,30]$. The overexpression of familial AD-related mutations in rats [31-33] has further advantages due to the closer evolutionary relationship between humans and rats; and, the relative higher behavioral complexity of rats compared to mice [34]. Here we report on the TgF344-AD model that overexpresses the human APPswe and PS1 $\triangle \mathrm{E} 9$ mutation under the mouse prion protein promoter [21] in the Fischer 344 rat. These TgF344-AD rats show age-related cerebral amyloidosis prior to the progressive deposition of $A \beta$ plaques, tauopathy, and neuronal loss leading to the manifestation of cognitive decline [32]. To date, however, only a few studies have focused on the microvascular bed in this and other rat Tg models of AD [35-40]. The present study is the first to assess capillary parameters using rigorous stereological methods to quantify differences in microvascular structure of $\mathrm{Tg}$ rats and non- $\mathrm{Tg}$ littermate (controls). We assessed between-group differences (Tg vs. non-Tg) and within-group differences for stereology parameters related to number and length of microvessels in hippocampal subregions, including total hippocampus (neuron cell layers, molecular layer, and white matter) and three hippocampal principal cells layers (PCL): 1) granule cell layer in dentate gyrus (DG); 2) pyramidal cell layer in CA3 combined with CA2 (CA 2/3); and 3) pyramidal cell layer in CA1. Second, we analyzed groups of $\mathrm{Tg}$ and non- $\mathrm{Tg}$ rats for within-group differences in microvascular parameters in these hippocampal subregions.

\section{MATERIAL AND METHODS}

\section{Animals and ethical statements}

Animals for this study were 12-month-old male rats from $\mathrm{TgF} 344-\mathrm{AD}(\mathrm{Tg})$ litters $(n=6)$ and non- $\mathrm{Tg}$ 
littermates $(n=5)$. The rats were housed in polysulfonate cages and maintained in a facility with $12-\mathrm{h}$ light/dark photoperiod at a temperature of $21 \pm 1^{\circ} \mathrm{C}$ with a relative humidity of $60 \%$. Standard commercial pellet diet and water were available ad libitum. All procedures were conducted in accordance with Act No. 246/1992 Coll. for the Protection of Animals against Cruelty under the supervision of the Animal Welfare Advisory Committee at the Ministry of Education, Youth and Sports of the Czech Republic (approval ID MSMT-11925/2016-3).

\section{PCR genotyping}

To confirm genotype a sample $(2 \mathrm{~mm})$ of tissue was taken from the tail of each rat (Total $n=11$ ) at the age of 8-10 weeks. Total purification of DNA was used according to the DNeasy Spin-Column Protocol (QIAGEN, Germany). The DNA of Tg rats included both APPsw and $\Delta$ exon 9 mutant human presenilin1 (PS1 $\Delta \mathrm{E} 9)$ genes while non-Tg rats were negative for either or both of these human mutations.

\section{Tissue processing}

The animals were sacrificed by transcardial perfusion of $0.1 \mathrm{M}$ phosphate buffered saline (PBS; $\mathrm{pH} 7.4$ ) followed by $4 \%$ paraformaldehyde in PBS. Brains were immersion fixed in $70 \%$ alcohol for $24 \mathrm{~h}$ at $4{ }^{\circ} \mathrm{C}$ then moved to $10 \%$ phosphate-buffered formalin for 30 days until embedding in paraffin blocks. Each block was microtome sectioned in the horizontal plane into $18-\mu \mathrm{m}$ thick serial sections $(\sim 350 \pm 16$ sections per brain). Every 30th section was mounted to glass slides, immunostained using anti-laminin (see below) and counterstained with hematoxylin. An unbiased systematic-random sampling design was used to generate a set of about 8 to 11 sections depending on length of each hippocampus.

\section{Immunohistochemistry}

Microvessels in the rat hippocampus were colorized using the polyclonal rabbit anti-laminin antibody (dilution 1:1000; Dako, Glostrup, Denmark, No. Z009701) with negative immunohistochemistry controls. Laminin is a marker for basal lamina present in all microvessels, including capillaries, venules, and arterioles. The sections were deparaffinized in xylene, rehydrated and successively treated with cooled acetone for $10 \mathrm{~min}$; Proteinase $\mathrm{K}$ for $6 \mathrm{~min}$ at room temperature; $5 \%$ normal goat serum for
$20 \mathrm{~min}$ at room temperature; primary antibody solution for $36 \mathrm{~h}$ at $4{ }^{\circ} \mathrm{C} ; 50 \%$ N-Histofine Simple Stain MAX PO (Multi, Nichirei Biosciences Inc., Tokyo, Japan) for $30 \mathrm{~min}$ at room temperature; and, colorized for 1-4 min in liquid diaminobenzidine (DAB) Substrate Chromogen System (Dako, DAB Chromogen). Immunostained sections were counterstained with Gill's hematoxylin. In the final step, sections were dehydrated in an alcohol series cleared by xylene, treated with mounting medium and coverslipped.

\section{Quantitative processing}

Stereological analyses were done blind to genotype with assistance from the Stereologer system (SRC Biosciences, Tampa, FL, USA) that consists of a Nikon Eclipse Ti-U microscope equipped with ProScan III motorized 3-axis step motor (Prior Electronics, UK) and standard optical lenses; high resolution digital imaging camera (Promicra 3-3CC); and the current version of Stereologer software (v11.0). As shown in Table 1, microvascular parameters included total region volume (Total $\mathrm{V}_{\text {Reg }}$ ); total number of microvascular segments (Total $\mathrm{N}_{\text {cap }}$ ); total number of microvascular endpoints (Total $\mathrm{N}_{\text {endp }}$ ); and total length of microvessels (Total $\mathrm{L}_{\mathrm{cap}}$ ). These parameters were analyzed in the following reference volumes: total hippocampus (principal cell layers, molecular layer and white matter) and three hippocampal principal cell layers (PCL): granule cell layer in DG; pyramidal cell layer in CA3 combined with CA2 (CA 2/3); and pyramidal cell layer in CA1 $[41,42]$. The regional volumes of each reference space were estimated using the Cavalieri principle with point counting $[43,44]$ with $10 \times$ objective (Plan Fluor, NA 0.45). Briefly, total volume of each region (Total V) was quantified from the sum of points $\left(\sum \mathrm{P}\right)$ hitting each subregion using Total $V=\sum \mathrm{P} \bullet$ area per point $(\mu \mathrm{m}) \bullet$ sampling interval $(\mathrm{k}) \bullet \mathrm{t}$, where $\mathrm{t}$ is the final post-processing section thickness $(\mu \mathrm{m})$.

A microvessel (capillary) was defined as a loop created between two vessel branches nodes (branch point or saddle point) of the vascular network [45, 46]. Total $\mathrm{N}_{\text {cap }}, \mathrm{N}_{\text {endp }}$, and $\mathrm{L}_{\text {cap }}$ were quantified using $60 \times$ oil objective (CFI, Plan Apo Lambda, NA 1.4) with $1-\mu \mathrm{m}$ guard zones at the top and bottom surfaces of each section. The total $\mathrm{N}_{\text {cap }}$ and Total $\mathrm{N}_{\text {endp }}$ were calculated according to Gundersen's Euler number based on the number of nodes (saddle points) counted by thin focal-plane z-axis scanning using the optical disector method [47, 48] (Fig. 1E). Number of Total $\mathrm{N}_{\text {cap }}$ was calculated as twice (2x) the num- 
Table 1

Complete quantitative parameters of the microvascular network of hippocampus of non- $\mathrm{Tg}$ control (non $\mathrm{Tg}$ ) and $\mathrm{TgF} 344-\mathrm{AD}$ rats ( $\mathrm{Tg}$ ). The stereological quantitative results are presented as the

\begin{tabular}{|c|c|c|c|c|c|c|c|c|c|c|c|c|}
\hline & & & $\begin{array}{l}\text { Volume }\left(\mathrm{mm}^{3}\right) \\
\left(\mathrm{mm}^{3}\right)\end{array}$ & $\begin{array}{l}\text { Volume } \\
\text { fractions }\end{array}$ & $\begin{array}{c}\text { Total } \\
\text { capillary } \\
\text { number }\end{array}$ & $\begin{array}{c}\text { Total } \\
\text { endpoints } \\
\text { number }\end{array}$ & $\begin{array}{c}\text { Capillary } \\
\text { density }\left(\# / \mathrm{mm}^{3}\right)\end{array}$ & $\begin{array}{c}\text { Endpoints } \\
\text { density }\left(\# / \mathrm{mm}^{3}\right)\end{array}$ & Length (m) & $\begin{array}{c}\text { Length } \\
\text { density } \\
\left(\mathrm{m} / \mathrm{mm}^{3}\right)\end{array}$ & $\begin{array}{c}\text { Mean } \\
\text { Length }(\mu \mathrm{m})\end{array}$ & $\begin{array}{c}\text { Diffusion } \\
\text { distance } \\
(\mu \mathrm{m})\end{array}$ \\
\hline \multirow{4}{*}{ 胥 } & \multirow[t]{2}{*}{ non $\mathrm{Tg}$} & mean & 46.40 & & $1,228,668$ & 622,140 & 27,147 & 13,742 & 75.99 & 1.67 & 62 & 7.19 \\
\hline & & $\pm \mathrm{SD}$ & 4.11 & & 358,030 & 178,329 & 9,990 & 4,996 & 22.81 & 0.60 & 9 & 1.36 \\
\hline & \multirow[t]{2}{*}{$\mathrm{Tg}$} & mean & 49.12 & & 932,315 & 472,076 & 19,220 & 9,732 & 82.80 & 1.72 & $95^{*}$ & 7.01 \\
\hline & & $\pm \mathrm{SD}$ & 6.39 & & 262,556 & 131,335 & 5,823 & 2,918 & 19.09 & 0.50 & 40 & 1.16 \\
\hline \multirow{3}{*}{ 水 } & \multirow[t]{2}{*}{ non $\mathrm{Tg}$} & mean & 2.00 & $4.37 \%$ & 77,976 & 39,345 & 39,872 & 20,127 & 3.55 & 1.87 & 58 & 6.65 \\
\hline & & $\pm \mathrm{SD}$ & 0.56 & $1.41 \%$ & 33,907 & 16,963 & 19,819 & 9,925 & 0.46 & 0.45 & 36 & 0.86 \\
\hline & \multirow[t]{2}{*}{$\mathrm{Tg}$} & mean & 1.40 & $2.81 \%$ & 90,070 & 45,691 & 62,976 & 32,049 & 4.49 & 3.03 & 59 & 5.62 \\
\hline & & $\pm \mathrm{SD}$ & 0.45 & $0.77 \%$ & 69,728 & 34,983 & 42,192 & 21,151 & 3.04 & 1.75 & 42 & 1.49 \\
\hline & \multirow[t]{2}{*}{ non $\mathrm{Tg}$} & mean & 1.56 & $3.36 \%$ & 253,061 & 126,891 & 145,097 & 72,785 & 2.94 & 1.90 & 41 & 6.54 \\
\hline \multirow{4}{*}{ 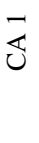 } & & $\pm \mathrm{SD}$ & 0.23 & $0.38 \%$ & 299,613 & 149,786 & 156,826 & 78,371 & 0.53 & 0.39 & 36 & 0.66 \\
\hline & \multirow[t]{2}{*}{$\mathrm{Tg}$} & mean & 1.29 & $2.62 \%$ & 28,355 & 19,218 & 22,542 & 15,292 & 3.08 & 2.48 & 111 & 5.74 \\
\hline & & $\pm \mathrm{SD}$ & 0.44 & $0.75 \%$ & 8,444 & 5,638 & 4,723 & 3,193 & 0.77 & 0.51 & 15 & 0.54 \\
\hline & \multirow[t]{2}{*}{ non $\mathrm{Tg}$} & mean & 2.05 & $4.43 \%$ & 69,840 & 35,283 & 35,192 & 17,776 & 3.40 & 1.70 & 53 & 7.28 \\
\hline \multirow{4}{*}{ Uִ } & & $\pm \mathrm{SD}$ & 0.30 & $0.68 \%$ & 37,760 & 18,875 & 20,617 & 10,315 & 1.34 & 0.74 & 11 & 1.71 \\
\hline & \multirow[t]{2}{*}{$\mathrm{Tg}$} & mean & 1.98 & $3.88 \%$ & 45,521 & 23,127 & 21,255 & 10,887 & $1.72^{*}$ & 1.08 & 63 & 9.31 \\
\hline & & $\pm \mathrm{SD}$ & 1.09 & $1.70 \%$ & 34,532 & 17,241 & 8,197 & 4,164 & 0.29 & 0.49 & 48 & 2.67 \\
\hline & \multirow[t]{2}{*}{ non $\mathrm{Tg}$} & mean & 5.61 & $12.17 \%$ & 148,864 & 400,877 & 27,060 & 74,552 & 9.88 & 1.78 & 68 & 6.76 \\
\hline \multirow{3}{*}{ 己ે } & & $\pm \mathrm{SD}$ & 0.60 & $1.78 \%$ & 39,724 & 254,667 & 8,621 & 51,663 & 1.51 & 0.37 & 11 & 0.69 \\
\hline & $\mathrm{Tg}$ & mean & $4.67^{\dagger}$ & $9.31 \%^{\dagger}$ & $163,946^{\dagger}$ & $88,036^{\dagger}$ & $35,911^{\dagger}$ & $19,393^{\dagger}$ & $9.30^{\dagger}$ & 2.07 & 60 & 6.39 \\
\hline & & $\pm \mathrm{SD}$ & 1.68 & $2.41 \%$ & 70,666 & 35,259 & 13,883 & 6,857 & 3.36 & 0.67 & 11 & 0.96 \\
\hline
\end{tabular}

*Significant in Mann-Whitney U Test; ${ }^{\dagger}$ Significant in Friedman ANOVA analysis. 

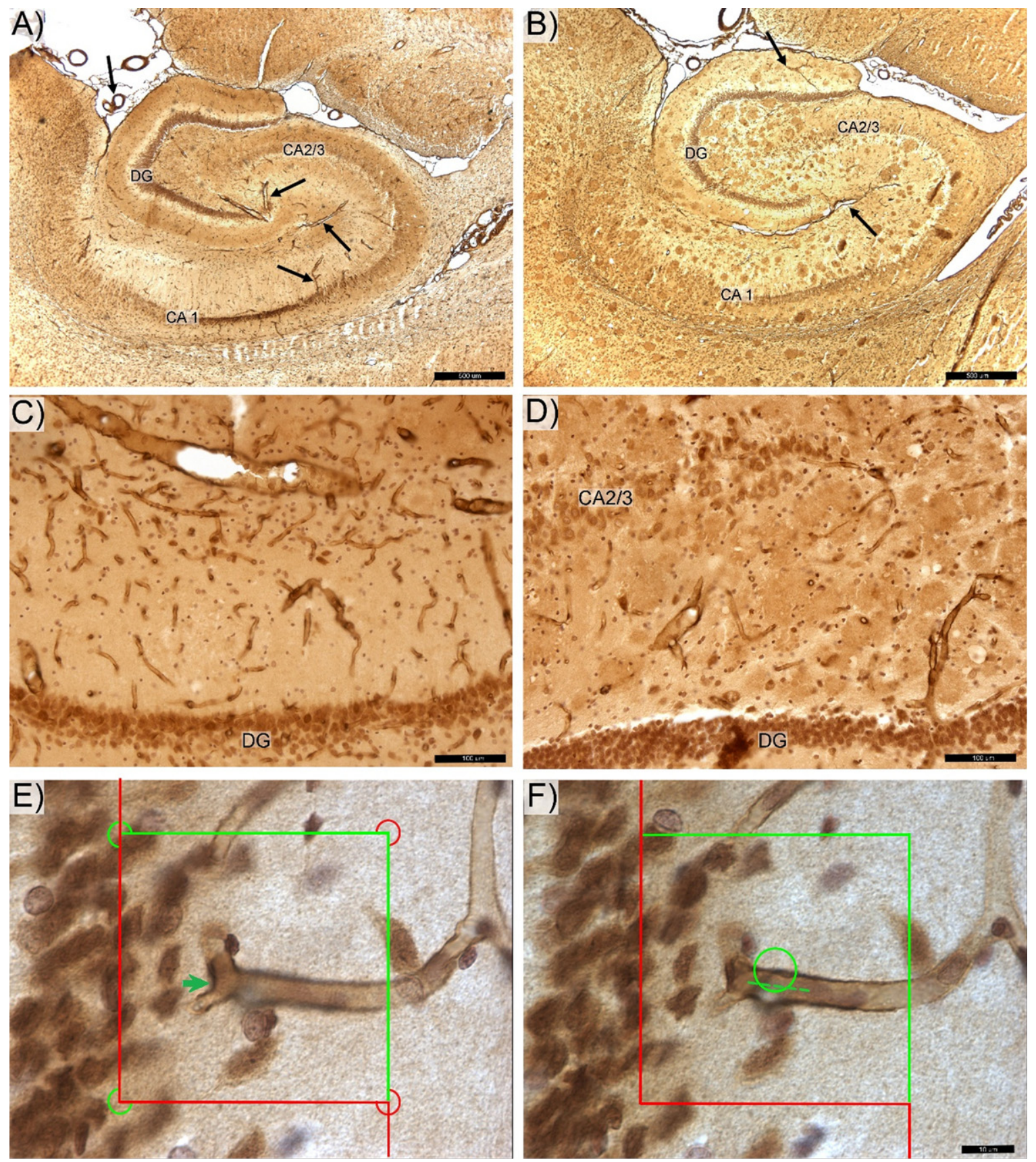

Fig. 1. Photomicrograph of the anti-laminin antibody labeled hippocampal microvessels in control (A,C) and transgenic (B,D) rats. DG -, CA 2/3-, and CA1-labeled respective zone of the pyramidal cells layer. The magisterial vessels, serve as the main source of hippocampal blood supply (black arrows). E) Total number of capillary segments (Euler number) was quantified by counting "saddle points" (green arrow) using the 3D optical disector probe. F) Total capillary length was determined using the Space Balls method based on number of intersections between surface of the virtual 3D sphere probe and centerline (spline) of each capillary (dotted line). Space bars: A,B - 500 $\mu$ m; C,D $100 \mu \mathrm{m} ; \mathrm{E}, \mathrm{F}-20 \mu \mathrm{m}$.

ber of nodes and the Total $\mathrm{N}_{\text {endp }}$ as the number of nodes $+1[9,44,49]$. Estimates of total microvascular length (Total $\mathrm{L}_{\text {cap }}$ ) were made using the isotropic sphere probe (Space Balls) where the total num- ber of sphere probe-capillary intersections $\left(\sum I\right)$ is directly proportional to the total microvascular length (Fig. 1F) [44, 50]. Average densities of microvascular number, microvascular branches, and microvascular 
length were calculated from Total $\mathrm{N}_{\text {cap }}$ and Total $\mathrm{L}_{\text {cap }}$, respectively, divided by the Total $\mathrm{V}$ of the respective reference space. Average microvascular length was calculated as the ratio of total microvascular length to total number of capillaries (Total $\mathrm{L}_{\text {cap }} /$ Total $\mathrm{N}_{\text {cap }}$ ). Finally, the potential diffusion distance of microvessels was determined in post-processing using the approach described in [46] with the gamma function calculated from average microvascular density. The coefficient of error (CE), a measure of sampling error, was estimated according to Gundersen et al., 1999 [51] with sampling across both hemispheres continued to a high level of sampling stringency [CE Total $V=0.03 ;$ CEs Total $\mathrm{N}_{\text {cap }}$ and Total $\left.\mathrm{L}_{\text {cap }}=0.13\right]$.

\section{Statistical analysis}

We carried out non-parametric statistical comparison with assistance from Statistica 13 (StatSoft, Inc., Tulsa, OK, USA) to test for between-group (Tg versus non-Tg) and within-group (e.g., DG versus CA subregions in $\mathrm{Tg}$ or non- $\mathrm{Tg}$ rats) differences in Total V, Total $\mathrm{N}_{\text {cap }}$, or Total $\mathrm{L}_{\text {cap }}$ and the potential diffusion distance of microvessels in neuron cell layers of hippocampus (DG, CA1, and CA2/3). The Mann-Whitney U-test was used to test for group effects (Tg versus non- $\mathrm{Tg}$ ). Within-group differences were assessed using Friedman ANOVA test followed by post-hoc testing using Wilcoxon signed-rank test. Correlations between parameters were quantified using the Spearman's coefficient. Difference of $p<0.05$ or lower was considered statistically significant.

\section{RESULTS}

Hippocampal sections from $\mathrm{Tg}$ rats show plaques with clear contours (Fig. 1B,D and Fig. 3) and prominent findings of abnormal hair-like capillaries in the vicinity of $A \beta$ plaques (Fig. 3). Between-group comparisons ( $\mathrm{Tg}$ versus non- $\mathrm{Tg}$ ) of stereology parameters reveal a $49 \%$ reduction in Total $\mathrm{L}_{\text {cap }}$ in DG for Tg rats (Mann-Whitney U, $p \leq 0.022$; Fig. 2C). Furthermore, there is a $53 \%$ increase in average length per capillary in entire hippocampus including PCL and white matter in Tg rats (Mann-Whitney $\mathrm{U}, p \leq 0.036$ ). There are no significant between-group differences in Total $\mathrm{V}$, Total $\mathrm{L}_{\text {cap }}$ and Total $\mathrm{N}_{\text {cap }}$ for entire hippocampus (Mann-Whitney U, $p>0.05$; see Table 1).

$\mathrm{Tg}$ rats show significant within-group differences in average $\mathrm{N}_{\text {cap }}$ density between PCL sublayers in $\mathrm{Tg}$ rats (Friedman, $p \leq 0.011$ ), with post-hoc confirmation of significantly higher average $\mathrm{N}_{\text {cap }}$ density in CA2/3 compared to CA1 (Wilcoxon, $p \leq 0.027$ ) and DG (Wilcoxon, $p \leq 0.027$ ). Second, $\mathrm{Tg}$ rats have significant within-group differences in the potential diffusion distance of microvessels (Friedman, $p \leq 0.042$ ), with post-hoc testing showing a significantly higher diffusion distance in DG comparing both CA2/3 and CA 1 subregions (Wilcoxon, $p \leq 0.046$; Fig. 2). In contrast, non-Tg rats showed no significant within-group differences in the average densities of $\mathrm{N}_{\text {cap }}$ and $\mathrm{L}_{\text {cap }}$ or the potential diffusion distance of microvessels in PCL subregions (Fig. 2; Friedman, $p>0.05$ ).

In $\mathrm{Tg}$ rats there are within-group differences in specific hippocampal subregions versus comparable subregions for the entire hippocampus. For instance, there is a significantly $56 \%$ higher $\mathrm{N}_{\text {cap }}$ density and $16 \%$ higher $\mathrm{L}_{\text {cap }}$ density in PCL as compared to the same parameters for the total hippocampus (Fig. 2 $\mathrm{E}, \mathrm{F}$; Wilcoxon, $p \leq 0.046)$. In contrast, non- $\mathrm{Tg}$ rats show significant within-group differences for $\mathrm{N}_{\text {cap }}$ and $\mathrm{L}_{\text {cap }}$ densities (Wilcoxon, $p \leq 0.05$ ) in combined specific subregions as compared to the entire hippocampus.

\section{DISCUSSION}

Blood vessels occupy about $8 \%$ of total volume of hippocampus in rats [52] with their spatial distributions as described earlier [6, 53]. From superficial hippocampal arteries these vessels form a network located for the most part in stratum oriens of the CA 1-3 zones and part of the molecular layer of DG zone (see Fig. 1A-C). Vessels extending from the inter-hippocampal artery in the hippocampal fissure provide blood to the internal part of the molecular layer of DG and the stratums lacunosum, moleculare, and radiatum of all CA subregions. The microvascular network of both pools then evenly spread along the large vessels and join in the PCL. Vascularization of PCL is characterized as deep microvascular network without preferential orientations [54], in contrast to white matter, with several large vessels that span all CA regions (Fig. 1) [6].

Previous studies in different cohorts of TgF344$\mathrm{AD}$ rats found evidence of neurodegeneration [32, $55,56]$. Other studies in TgF344-AD rats reported electrophysiological changes starting $[57,58]$ and increase at glutamate receptors density in CA regions [59] at 6 months of age with no impairments in cognitive function until 10-12 months [32, 60]. Longer 


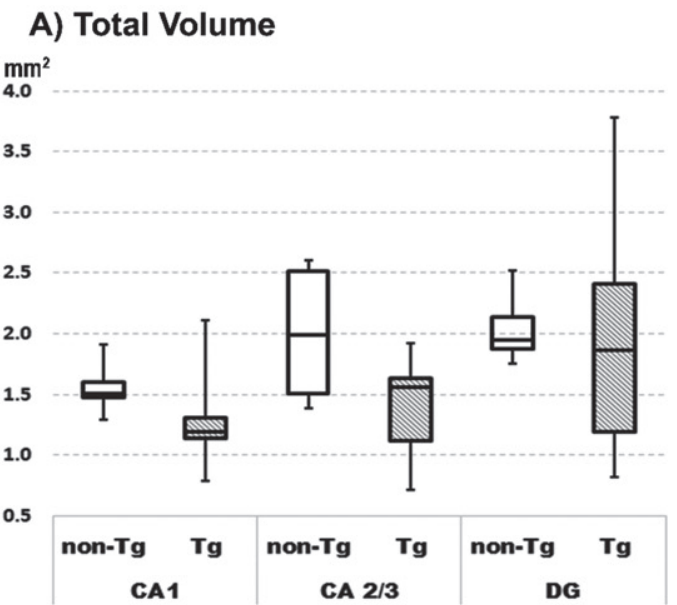

\section{C) Total Capillary Length}

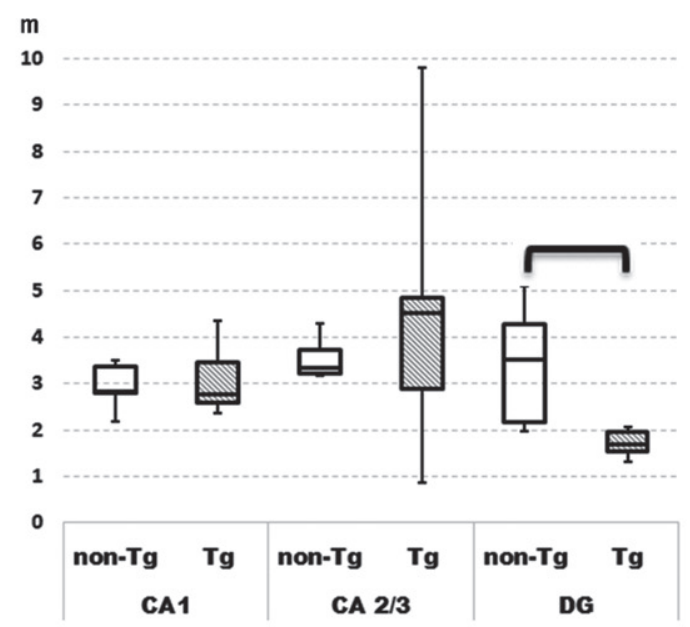

E) Length density of Capillary

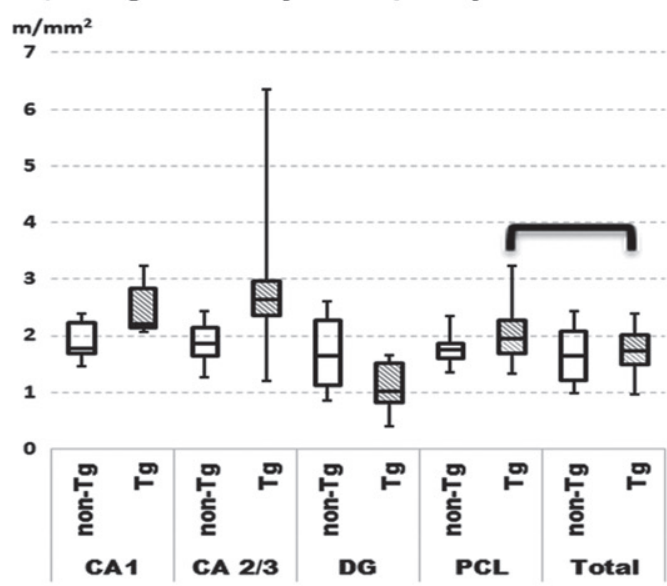

\section{B) Total Capillary Number}

$\times 10.000$

30

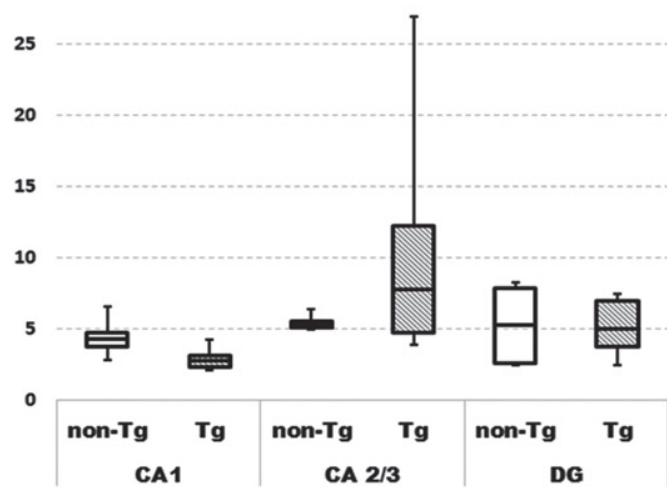

D) Diffusion Distance

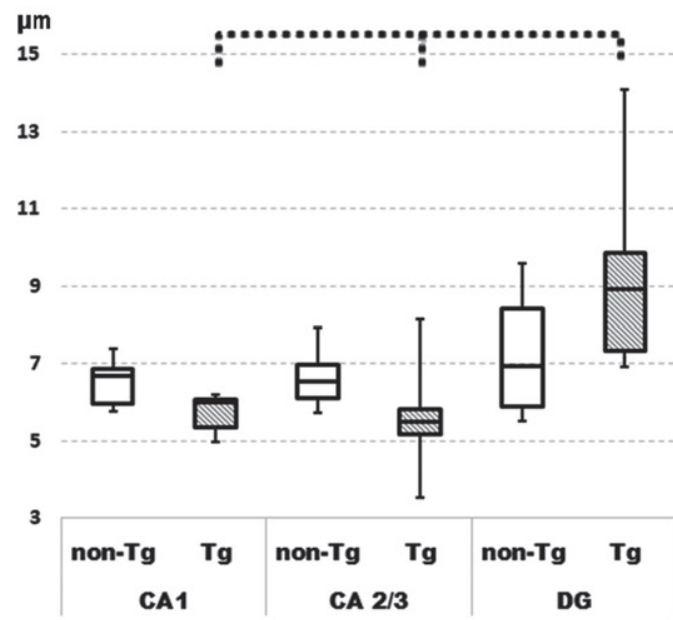

F) Number density of Capillary $\times 10000 / \mathrm{mm}^{2}$

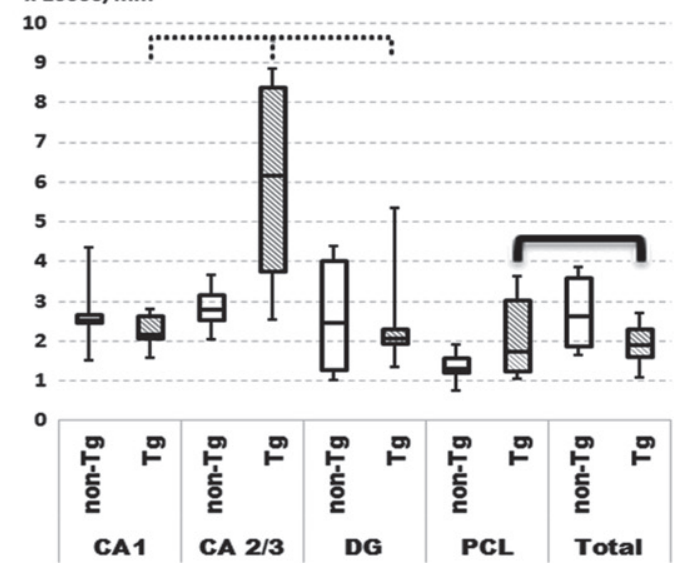

Fig. 2. Quartile box plot of selected quantitative parameters for the microvascular network in anatomical subregions of pyramidal cell layer of hippocampus in non-transgenic (non-Tg) and transgenic rats ( $\mathrm{Tg}$ ). Significant results of the Mann-Whitney U-test are showed with bold lines $(p \leq 0.05)$. Significant results of the Friedman ANOVA and Kendall coefficient of concordance within group are showed with bold dotted lines $(p \leq 0.05)$. The stereological quantitative results are presented as median values with boxes that span the limits of the first and third quartiles and whiskers that span the minimum and maximum values for each group. 

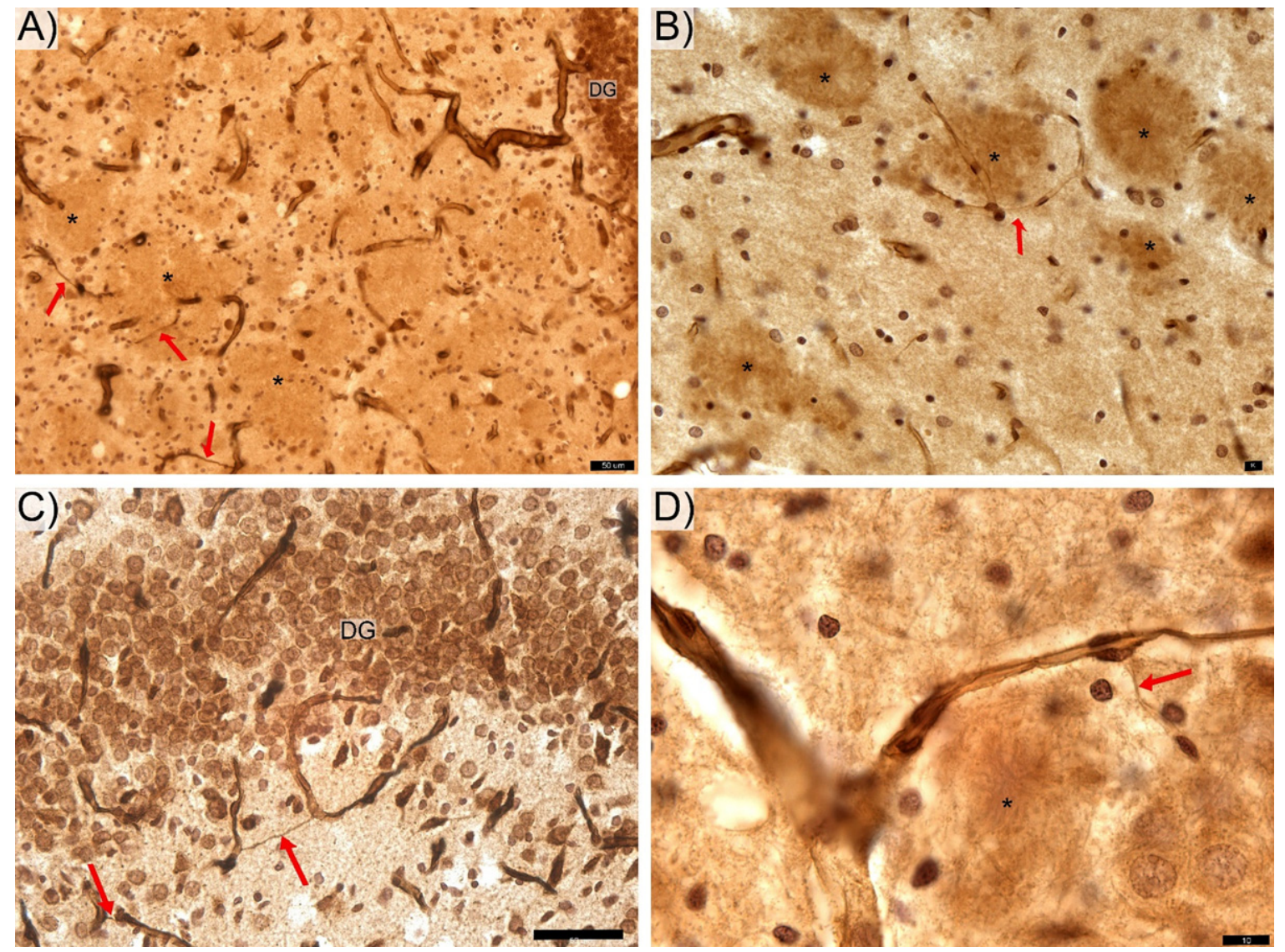

Fig. 3. Features of thin hair-like capillaries (red arrows) commonly find in TgF rats. DG-, CA 2/3-, and CA1-labeled respective zone of the pyramidal cells layer. The anti-laminin antibody labeled hippocampal sections from the transgenic rats contain areas of with clear contours (*) appear as likely locations of A $\beta$ deposition. Space bars: A,C $-50 \mu \mathrm{m} ; \mathrm{B}, \mathrm{D}-10 \mu \mathrm{m}$.

lived TgF344-AD rats after 12 months of age displayed pronounced deficits in memory and navigation [61-63] combine with progressive loss of hippocampal norepinephrine levels, especially in DG [60]. Our present study of male 12-month-old TgF344$\mathrm{AD}$ rats found a significant $49 \%$ reduction in Total $\mathrm{L}_{\text {cap }}$ in DG with increases in mean diffusion distance of microvessels (Fig. 2). This finding can also be enhanced by slight decrease in $\mathrm{N}_{\text {cap }}$ and the volume of DG area. Because DG is a region with high neurogenic ability and neurogenic potential, we speculated that this finding provides an anatomical basis for reported evidence of neurodegeneration, electrophysiological disturbances, and cognitive decline [64] in $\mathrm{TgF} 344-\mathrm{AD}$ rats, especially in the early-stage of AD development.

Though the present study did not aim to stain the $A \beta$ plaques, rings of microglial cells surrounding areas of with clear contours (Fig. 1B,D and Fig. 3 ) appear as likely locations of $A \beta$ deposition [31,
32]. The generally non-uniform distribution of these apparent $A \beta$ plaques in the hippocampus is similar to that reported by others $[21,32]$. The area of hippocampus coverage by $\mathrm{A} \beta$ plaque gradually increasing from $\sim 0 \%$ in 6-month-old rats [32] to $\sim 3 \%$ in 12-17-month-old rats [21, 61]. Our findings of thin hair-like capillaries (Fig. 3) in proximity to apparent amyloid plaques in the hippocampus of this $\mathrm{Tg}$ rat model show similarities to those reported in the hippocampal microvascular system of Tg murine models of $\mathrm{AD}[8,65]$. These common observations in $\mathrm{Tg}$ rodent models of $\mathrm{AD}$ provides indirect evidence of the cerebral amyloid angiopathy found in hippocampal microcirculation of $\mathrm{AD}$ patients at postmortem examination $[21,65,66]$.

A general trend in favor of decreasing volumes for all principal cells sublayers findings in our study (see Fig. 2A and Table 1) provide evidence of degeneration in $\mathrm{Tg}$ rats corresponds to that reported by other groups [31-33], including a denser capillary network 
in PCL comparing to the entire hippocampus of Tg rats. Furthermore, the average microvessels length in the denser microvascular network of hippocampus in $\mathrm{Tg}$ rats was twice that in the hippocampus of non-Tg rats. Among the possible explanations is microcirculatory remodeling in response to stress or injury caused by $A \beta$ deposition in the hippocampus of Tg rats [67-69] to maintain the principal cells by limiting metabolic activity of white matter. The nonsignificantly higher average length of vessels in CA1 and DG areas combined with fluctuations of $\mathrm{N}_{\text {cap }}$ and $\mathrm{L}_{\text {cap }}$ in CA2/3 provide further support for this view.

We also found apparent discrepancies with earlier reports in $\mathrm{Tg}$ rodent models of $\mathrm{AD}$. For example, previous stereology studies of microvascular in 7month-old Tg APP/PS1 mice [9, 64] report reductions in the total $\mathrm{N}_{\text {cap }}$ in white matter and a $45 \%$ reduction in total $\mathrm{L}_{\text {cap }}$ up to $45 \%$ and reductions in hippocampal volume up to $30 \%$ [8]; in contrast, we did not find these effects in 12-month-old male TgF344-AD. Furthermore, we did not detect changes in mean $\mathrm{L}_{\text {cap }}$ density in the CA1 as reported in Flinderssensitive line rats $[67,69,70]$. Possible reasons for these discrepancies include differences in the relative vulnerabilities of the microsvascular systems in hippocampus of mice and rats in response to $A \beta$ deposition, as well as potential differences in the time course of these AD-type changes to manifest in different species of rodents. Further studies of the time course of these changes would help to clarify the similarities and differences of these changes in mice and rats in relation to similar changes in humans with AD.

Here we described previously unreported lower Total $\mathrm{L}_{\text {cap }}$ in DG of $\mathrm{Tg}$ rats, which may be the results of genetic features or possibly angiogenic responses to $A \beta$ deposition. From about 9 months of age these vessel walls begin to lose their elasticity [71] and appear to undergo penetration by $\mathrm{A} \beta$ aggregates $[18,20,21]$. The cytoskeletal proteins desmin and $\alpha$-smooth muscle actin ( $\alpha$-SMA) in pericytes become upregulated [21], which slows down the active redistribution of local blood flow [72]. Local diffusion changes could promote transient fluctuation of the blood pressure [71] that may induce or exacerbate cerebrovascular damage and progression resulting from $\mathrm{A} \beta$ deposition $[73,74]$. Furthermore, trophic disbalance of the granular cells layer in DG may lead to synaptic disruptions [17, 60, 75] and weakened effectiveness of synaptic transmission to projections in CA subregions [76].
In conclusion, our stereological studies of the microvascular network in the hippocampus find both between-group effects in 12-month-old male Tg rats compared to age- and sex-matched non-Tg controls, together with subregional differences (i.e., withingroup effects) in $\mathrm{Tg}$ rats that are not present in non-Tg. These findings include significantly lower Total $\mathrm{L}_{\text {cap }}$ in the DG region and 53\% higher average capillary length (Total $\mathrm{L}_{\text {cap }} /$ Total $\mathrm{N}_{\text {cap }}$ ) for total hippocampus in $\mathrm{Tg}$ compared to non-Tg rats. Among within-group differences in $\mathrm{Tg}$ rats are differences in number and length density of capillary in neuron cells layer with the most marked differences in the DG. Similarities with AD-type microcirculatory changes reported in humans suggest the TgF344-AD rat model provides a useful in-vivo model for enhancing understanding and pre-clinical drug discovery for future studies of the cerebral amyloid angiopathy associated with $\mathrm{AD}$ in humans.

\section{ACKNOWLEDGMENTS}

We would like to thanks Dr. Karel Jezek and Prof. Zybnek Tonar for their general support of this project.

This study was supported by the Charles University Research Fund (Progres Q39) and the Project No. CZ.02.1.01/0.0/0.0/16_019/0000787 "Fighting Infectious Diseases", awarded by the Ministry of Education, Youth and Sports of the Czech Republic. This study was also by the Alzheimer Foundation Czech Republic and the Avast Foundation. Dr. Mouton is supported by research grants from the Florida High Tech Corridor Foundation (U.S.A.) and grant \#1926990 from the National Science Foundation (USA).

Authors' disclosures available online (https:// www.j-alz.com/manuscript-disclosures/21-0738r1).

\section{REFERENCES}

[1] Nichols MR, St-Pierre MK, Wendeln AC, Makoni NJ, Gouwens LK, Garrad EC, Sohrabi M, Neher JJ, Tremblay ME, Combs CK (2019) Inflammatory mechanisms in neurodegeneration. J Neurochem 149, 562-581.

[2] Kolinko Y, Krakorova K, Cendelin J, Tonar Z, Kralickova M (2015) Microcirculation of the brain: Morphological assessment in degenerative diseases and restoration processes. Rev Neurosci 26, 75-93.

[3] Kamara DM, Gangishetti U, Gearing M, Willis-Parker M, Zhao L, Hu WT, Walkerx LC (2018) Cerebral amyloid angiopathy: Similarity in African-Americans and Caucasians with Alzheimer's disease. J Alzheimers Dis 62, 1815-1826. 
[4] Ellis RJ, Olichney JM, Thal LJ, Mirra SS, Morris JC, Beekly D, Heyman A (1996) Cerebral amyloid angiopathy in the brains of patients with Alzheimer's disease: The CERAD experience, Part XV. Neurology 46, 1592-1596.

[5] Strozyk D, Dickson DW, Lipton RB, Katz M, Derby CA, Lee S, Wang C, Verghese J (2010) Contribution of vascular pathology to the clinical expression of dementia. Neurobiol Aging 31, 1710-1720.

[6] Grivas I, Michaloudi H, Batzios C, Chiotelli M, Papatheodoropoulos C, Kostopoulos G, Papadopoulos GC (2003) Vascular network of the rat hippocampus is not homogeneous along the septotemporal axis. Brain Res 971, 245-249.

[7] Tatu L, Vuillier F (2014) Structure and vascularization of the human hippocampus. Front Neurol Neurosci 34, 18-25.

[8] Gama Sosa MA, Gasperi RD, Rocher AB, Wang AC, Janssen WG, Flores T, Perez GM, Schmeidler J, Dickstein DL, Hof PR, Elder GA (2010) Age-related vascular pathology in transgenic mice expressing presenilin 1-associated familial Alzheimer's disease mutations. Am J Pathol 176, 353-368

[9] Lee GD, Aruna JH, Barrett PM, Lei DL, Ingram DK, Mouton PR (2005) Stereological analysis of microvascular parameters in a double transgenic model of Alzheimer's disease. Brain Res Bull 65, 317-322.

[10] Bouras C, Kövari E, Herrmann FR, Rivara CB, Bailey TL, von Gunten A, Hof PR, Giannakopoulos P (2006) Stereologic analysis of microvascular morphology in the elderly: Alzheimer disease pathology and cognitive status. $\mathrm{J} \mathrm{Neu}$ ropathol Exp Neurol 65, 235-244.

[11] Price JM, Chi X, Hellermann G, Sutton ET (2001) Physiological levels of beta-amyloid induce cerebral vessel dysfunction and reduce endothelial nitric oxide production. Neurol Res 23, 506-512.

[12] Winkler EA, Sengillo JD, Sullivan JS, Henkel JS, Appel SH, Zlokovic BV (2013) Blood-spinal cord barrier breakdown and pericyte reductions in amyotrophic lateral sclerosis. Acta Neuropathol 125, 111-120.

[13] Charidimou A, Gang Q, Werring DJ (2018) Sporadic cerebral amyloid angiopathy revisited: Recent insights into pathophysiology and clinical spectrum. J Neurol Neurosurg Psychiatry 83, 124-137.

[14] Di Marco LY, Farkas E, Martin C, Venneri A, Frangi AF (2015) Is vasomotion in cerebral arteries impaired in Alzheimer's disease? J Alzheimers Dis 46, 35-53.

[15] de Wit NM, Snkhchyan H, den Hoedt S, Wattimena D, de Vos R, Mulder MT, Walter J, Martinez-Martinez P, Hoozemans JJ, Rozemuller AJ, de Vries HE (2017) Altered sphingolipid balance in capillary cerebral amyloid angiopathy. J Alzheimers Dis 60, 795-807.

[16] Chen F, Ardalan M, Elfving B, Wegener G, Madsen TM, Nyengaard JR (2018) Mitochondria are critical for BDNFmediated synaptic and vascular plasticity of Hippocampus following repeated electroconvulsive seizures. Int J Neuropsychopharmacol 21, 291-304.

[17] Smith LA, McMahon LL (2018) Deficits in synaptic function occur at medial perforant path-dentate granule cell synapses prior to Schaffer collateral-CA1 pyramidal cell synapses in the novel TgF344-Alzheimer's disease rat model. Neurobiol Dis 110, 166-179.

[18] Hall CN, Reynell C, Gesslein B, Hamilton NB, Mishra A, Sutherland BA, O'Farrell FM, Buchan AM, Lauritzen M, Attwell D (2014) Capillary pericytes regulate cerebral blood flow in health and disease. Nature 508, 55-60.
[19] Kolinko Y, Kralickova M, Tonar Z (2018) The impact of pericytes on the brain and approaches for their morphological analysis. J Chem Neuroanat 91, 35-45.

[20] Bergers G, Song S (2005) The role of pericytes in bloodvessel formation and maintenance. Neuro Oncol 7, 452-464.

[21] Joo IL, Lai AY, Bazzigaluppi P, Koletar MM, Dorr A, Brown ME, Thomason LA, Sled JG, McLaurin J, Stefanovic B (2017) Early neurovascular dysfunction in a transgenic rat model of Alzheimer's disease. Sci Rep 12, 46427.

[22] Sengillo JD, Winkler EA, Walker CT, Sullivan JS, Johnson M, Zlokovic BV (2013) Deficiency in mural vascular cells coincides with blood-brain barrier disruption in Alzheimer's disease. Brain Pathol 23, 303-310.

[23] Lai AY, Dorr A, Thomason LA, Koletar MM, Sled JG, Stefanovic B, McLaurin J (2015) Venular degeneration leads to vascular dysfunction in a transgenic model of Alzheimer's disease. Brain 138, 1046-58.

[24] Kumar-Singh S (2008) Cerebral amyloid angiopathy: Pathogenetic mechanisms and link to dense amyloid plaques. Genes Brain Behav 1, 67-82.

[25] Revesz T, Ghiso J, Lashley T, Plant G, Rostagno A, Frangione B, Holton JL (2003) Cerebral amyloid angiopathies: A pathologic, biochemical, and genetic view. J Neuropathol Exp Neurol 62, 885-898.

[26] Fonseca MB, Solá S, Xavier JM, Dionísio PA, Rodrigues CM (2013) Amyloid $\beta$ peptides promote autophagydependent differentiation of mouse neural stem cells: A $\beta$-mediated neural differentiation. Mol Neurobiol 48, 829840.

[27] Voorhees JR, Remy MT, Erickson CM, Dutca LM, Brat DJ, Pieper AA (2019) Occupational-like organophosphate exposure disrupts microglia and accelerates deficits in a rat model of Alzheimer's disease. NPJ Aging Mech Dis 5, 3 .

[28] Desai BS, Schneider JA, Li JL, Carvey PM, Hendey B (2009) Evidence of angiogenic vessels in Alzheimer's disease. J Neural Transm 116, 587-597.

[29] Kannurpatti SS, Motes MA, Rypma B, Biswal BB (2010) Neural and vascular variability and the fMRI-BOLD response in normal aging. Magn Reson Imaging 28, 466476.

[30] Sasaguri H, Nilsson P, Hashimoto S, Nagata K, Saito T, De Strooper B, Hardy J, Vassar R, Winblad B, Saido TC (2017) APP mouse models for Alzheimer's disease preclinical studies. EMBO J 36, 2473-2487.

[31] Jankowsky JL, Slunt HH, Ratovitski T, Jenkins NA, Copeland NG, Borchelt DR (2001) Co-expression of multiple transgenes in mouse CNS: A comparison of strategies. Biomol Eng 17, 157-165.

[32] Cohen RM, Rezai-Zadeh K, Weitz TM, Rentsendorj A, Gate D, Spivak I, Bholat Y, Vasilevko V, Glabe CG, Breunig JJ, Rakic P, Davtyan H, Agadjanyan MG, Kepe V, Barrio JR, Bannykh S, Szekely CA, Pechnick RN, Town T (2013) A transgenic Alzheimer rat with plaques, tau pathology, behavioral impairment, oligomeric $\mathrm{a} \beta$, and frank neuronal loss. J Neurosci 33, 6245-6256.

[33] Koulousakis P, van den Hove D, Visser-Vandewalle V, Sesia $T$ (2020) Cognitive improvements after intermittent deep brain stimulation of the nucleus basalis of meynert in a transgenic rat model for Alzheimer's disease: A preliminary approach. J Alzheimers Dis 73, 461-466.

[34] Yang S, Smit AF, Schwartz S, Chiaromonte F, Roskin KM, Haussler D, Miller W, Hardison RC (2004) Patterns of insertions and their covariation with substitutions in the rat, mouse, and human genomes. Genome Res 14, 517-527. 
[35] Heggland I, Storkaas IS, Soligard HT, Kobro-Flatmoen A, Witter MP (2015) Stereological estimation of neuron number and plaque load in the hippocampal region of a transgenic rat model of Alzheimer's disease. Eur J Neurosci 41, 1245-1262.

[36] Wang JQ, Yin J, Song YF, Zhang L, Ren YX, Wang DG, Gao LP, Jing YH (2014) Brain aging and AD-like pathology in streptozotocin-induced diabetic rats. J Diabetes Res 2014, 796840.

[37] Madhavadas S, Subramanian S (2017) Cognition enhancing effect of the aqueous extract of Cinnamomum zeylanicum on non-transgenic Alzheimer's disease rat model: Biochemical, histological, and behavioural studies. Nutr Neurosci $\mathbf{2 0}$, 526-537.

[38] Ahmad A, Murthy M, Greiner RS, Moriguchi T, Salem $\mathrm{N}$ (2002) A decrease in cell size accompanies a loss of docosahexaenoate in the rat hippocampus. Nutr Neurosci 5, 103-113.

[39] Fitting S, Booze RM, Hasselrot U, Mactutus CF (2010) Dose-dependent long-term effects of Tat in the rat hippocampal formation: A design-based stereological study. Hippocampus 20, 469-480.

[40] Corbett NJ, Gabbott PL, Klementiev B, Davies HA, Colyer FM, Novikova T, Stewart MG (2013) Amyloid-beta induced CA1 pyramidal cell loss in young adult rats is alleviated by systemic treatment with FGL, a neural cell adhesion molecule-derived mimetic peptide. PLoS One 8, e71479.

[41] West MJ, Slomianka L, Gundersen HJ (1991) Unbiased stereological estimation of the total number of neurons in thesubdivisions of the rat hippocampus using the optical fractionator. Anat Rec 4, 482-497.

[42] Paxinos G, Watson C (2005) The Rat Brain in Stereotaxic Coordinates. Elsevier Academic Press, Amsterdam, Boston.

[43] Mouton PR (2011) Unbiased Stereology: A Concise Guide 1st edn. Johns Hopkins University Press, Baltimore.

[44] Mouton PR (2002) Principles and Practices of Unbiased Stereology: An Introduction for Bioscientists 1st edn. Johns Hopkins University Press, Baltimore.

[45] Løkkegaard A, Nyengaard JR., West MJ (2001) Stereological estimates of number and length of capillaries in subdivisions of the human hippocampal region. Hippocampus 11, 726-740.

[46] Kolinko Y, Cendelin J, Kralickova M, Tonar Z (2016) Smaller absolute quantities but greater relative densities of microvessels are associated with cerebellar degeneration in Lurcher mice. Front Neuroanat 10, 35.

[47] Gundersen HJ, Boyce RW, Nyengaard JR, Odgaard A (1993) The Conneulor: Unbiased estimation of connectivity using physical disectors under projection. Bone 14, 217-222.

[48] Sterio DC (1984) The unbiased estimation of number and sizes of arbitrary particles using the disector. J Microsc 134, 127-136.

[49] Nyengaard JR, Marcussen N (1993) The number of glomerular capillaries estimated by an unbiased and efficient stereological method. J Microsc 171, 27-37.

[50] West MJ (2018) Space balls revisited: Stereological estimates of length with virtual isotropic surface probes. Front Neuroanat 12, 49.

[51] Gundersen HJ, Jensen EB, Kiêu K, Nielsen J (1999) The efficiency of systematic sampling in stereologyreconsidered. J Microsc 193, 199-211.

[52] Gutierre RC, Vannucci Campos D, Mortara RA, Coppi AA, Arida RM (2017) Reflection imaging of China ink-perfused brain vasculature using confocal laser-scanning microscopy after clarification of brain tissue by the Spalteholz method. $J$ Anat 230, 601-606.

[53] Ogawa K, Suzuki Y, Akimoto T, Shiobara K, Hara M, Morita A, Kamei S, Soma M (2018) Relationship between cytotoxicity in the hippocampus and an Abnormal high intensity area on the diffusion-weighted images of three patients with transient global amnesia. Intern Med 57, 2631-2639.

[54] Kubíková T, Kochová P, Tomášek P, Witterd K, Tonar Z (2018) Numerical and length densities of microvessels in the human brain: Correlation with preferential orientation of microvessels in the cerebral cortex, subcortical grey matter and white matter, pons and cerebellum. J Chem Neuroanat 88, 22-32.

[55] Leplus A, Lauritzen I, Melon C, Kerkerian-Le Goff L, Fontaine D, Checler F (2019) Chronic fornix deep brain stimulation in a transgenic Alzheimer's rat model reduces amyloid burden, inflammation, and neuronal loss. Brain Struct Funct 224, 363-372.

[56] Kelly SC, McKay EC, Beck JS, Collier TJ, Dorrance AM, Counts SE (2019) Locus coeruleus degeneration induces forebrain vascular pathology in a transgenic rat model of Alzheimer's disease. J Alzheimers Dis 70, 371-388.

[57] Stoiljkovic M, Kelley C, Stutz B, Horvath TL, Hajós M (2019) Altered cortical and hippocampal excitability in TgF344-AD rats modeling Alzheimer's disease pathology. Cereb Cortex 29, $2716-2727$.

[58] Anckaerts C, Blockx I, Summer P, Michael J, Hamaide J, Kreutzer C, Boutin H, Couillard-Després S, Verhoye M, Van der Linden A (2019) Early functional connectivity deficits and progressive microstructural alterations in the TgF344AD rat model of Alzheimer's disease: A longitudinal MRI study. Neurobiol Dis 124, 93-107.

[59] Smith LA, McMahon LL (2018) Corrigendum to "Deficits in synaptic function occur at medial perforant path-dentate granule cell synapses prior to Schaffer collateral-CA1 pyramidal cell synapses in the novel TgF344-Alzheimer's Disease Rat Model" [Neurobiology of Disease, 110, 2018, 166-179]. Neurobiol Dis 118, 177-178.

[60] Rorabaugh JM, Chalermpalanupap T, Botz-Zapp CA, Fu VM, Lembeck NA, Cohen RM, Weinshenker D (2017) Chemogenetic locus coeruleus activation restores reversal learning in a rat model of Alzheimer's disease. Brain 140, 3023-3038.

[61] Berkowitz LE, Harvey RE, Emma Drake E, Thompson SM, Clark BJ (2018) Progressive impairment of directional and spatially precise trajectories by $\mathrm{TgF} 344-$ Alzheimer's disease rats in the Morris Water Task. Sci Rep 8, 16153.

[62] Tudela R, Muñoz-Moreno E, Sala-Llonch R, López-Gil X, Soria G (2019) Resting state networks in the TgF344-AD rat model of alzheimer's disease are altered from early stages. Front Aging Neurosci 11, 213.

[63] Sare RM, Cooke SK, Krych L, Zerfas PM, Cohen RM, Smith CB (2020) Behavioral phenotype in the TgF344-AD rat model of Alzheimer's disease. Front Neurosci 14, 601.

[64] Zhang Y, Chao FL, Zhang L, Jiang L, Zhou CN, Chen LM, Lu W, Jiang R, Tang Y (2019) Quantitative study of the capillaries within the white matter of the $\mathrm{Tg} 2576$ mouse model of Alzheimer's disease. Brain Behav 9, e01268.

[65] Bailey TL, Rivara CB, Rocher AB, Hof PR (2004) The nature and effects of cortical microvascular pathology in aging and Alzheimer's disease. Neurol Res 26, 573-578.

[66] Zarow C, Barron E, Chui HC, Perlmutter LS (1997) Vascular basement membrane pathology and Alzheimer's disease. Ann N Y Acad Sci 826, 147-160. 
[67] Ardalan M, Wegener G, Polsinelli B, Madsen TM, Nyengaard JR (2016) Neurovascular plasticity of the hippocampus one week after a single dose of ketamine in genetic rat model of depression. Hippocampus 26, 14141423.

[68] Pearson-Leary J, Eacret D, Chen R, Takano H, Nicholas, B, Bhatnagar S (2017) Inflammation and vascular remodeling in the ventral hippocampus contributes to vulnerability to stress. Transl Psychiatry 7, e1160.

[69] Ardalan M, Wegener G, Rafati AH, Nyengaard JR (2017) S-ketamine rapidly reverses synaptic and vascular deficits of hippocampus in genetic animal model of depression. Int J Neuropsychopharmacol 20, 247-256.

[70] Fenghua C, Maryam A, Betina E, Gregers W, Torsten MM, Jens RN (2018) Mitochondria are critical for BDNFmediated synaptic and vascular plasticity of hippocampus following repeated electroconvulsive seizures. Int J Neuropsychopharmacol 21, 291-304.

[71] Bazzigaluppi P, Beckett TL, Koletar MM, Hill ME, Lai A, Trivedi A, Thomason L, Dorr A, Gallagher D, Librach CL, Joo IJ, JoAnne McLaurin J, Stefanovic B (2019) Combinatorial treatment using umbilical cord perivascular cells and $\mathrm{A} \beta$ clearance rescues vascular function following transient hypertension in a rat model of Alzheimer disease. Hypertension 74, 1041-1051.
[72] Ndode-Ekane XE, Hayward N, Gröhn O, Pitkänen A (2010) Vascular changes in epilepsy: Functional consequences and association with network plasticity in pilocarpine-induced experimental epilepsy. Neuroscience 166, 312-332.

[73] Hu N, Gao L, Jiang Y, Wei S, Shang S, Chen C, Dang L, Wang J, Huo K, Deng M, Wang J, Qu Q (2020) The relationship between blood lipids and plasma amyloid beta is depend on blood pressure: A population-based crosssectional study. Lipids Health Dis 19, 8.

[74] Oveisgharan S, Capuano AW, Kapasi A, Buchman AS, Schneider JA, Bennett DA, Arvanitakis Z (2020) Association of low systolic blood pressure with postmortem amyloid- $\beta$ and tau. $J$ Alzheimers Dis 78, 1755-1764.

[75] Hansen N, Manahan-Vaughan D (2015) Locus coeruleus stimulation facilitates long-term depression in the dentate gyrus that requires activation of $\beta$-adrenergic receptors. Cereb Cortex 25, 1889-1896.

[76] Galloway CR, Ravipati K, Singh S, Lebois EP, Cohen RM, Levey AI, Manns JR (2018) Hippocampal place cell dysfunction and the effects of muscarinic M1 receptor agonism in a rat model of Alzheimer's disease. Hippocampus $\mathbf{2 8}$, 568-585. 